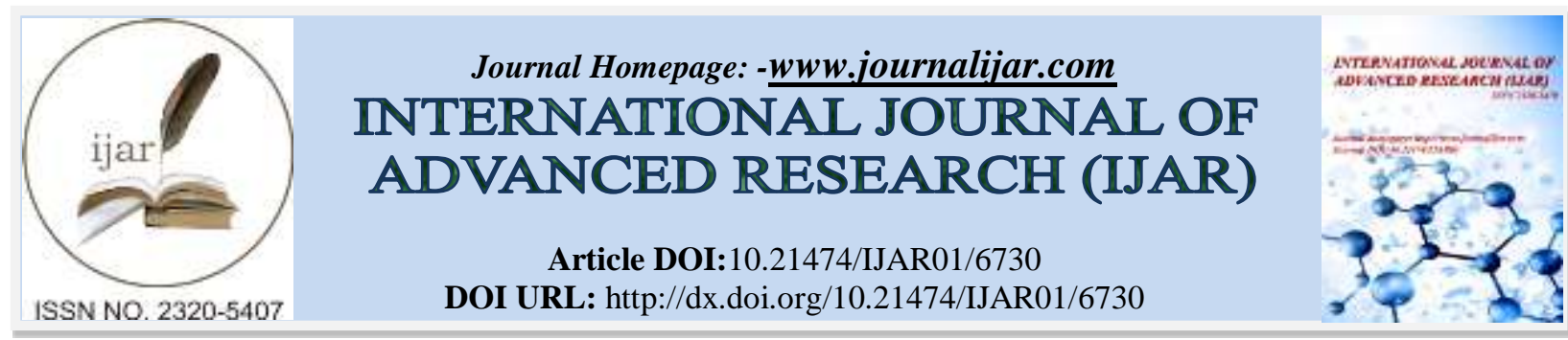

RESEARCH ARTICLE

\title{
CLINICAL OUTCOMES AFTER SWITCHING FROM PREMIXED INSULIN TO BASAL INSULIN IN PATIENTS WITH TYPE 2 DIABETES MELLITUS IN EVERYDAY CARE IN THE GULF REGION: THE I-TALENT STUDY.
}

\author{
Hubert Penninckk ${ }^{1}$, Sameer AL-Shammari ${ }^{2}$ and Ahmed Mansour ${ }^{3}$. \\ 1 Consultant Endocrinology in Endocrinology and Diabetes, American Hospital Dubai. \\ 2 Head of the Endocrine unit, Al Jahra Hospital. \\ 3 Medical Manager, Sanofi.
}

\section{Manuscript Info}

Manuscript History

Received: 12 January 2018

Final Accepted: 14 February 2018

Published: March 2018

Keywords:-

Insulin glargine, premixed insulin, type

2 diabetes, observational study, Gulf countries.

\section{Abstract}

Type 2 diabetes mellitus (T2DM) prevalence in the Middle East is one of the highest in the world and glycemic control is frequently poor. Switching from other insulin regimens to a basal insulin has been shown to improve glycemic control in Europe and North America, but the benefits of such a strategy in Middle Eastern populations have not been demonstrated sufficiently. Our study aimed to describe the evolution of glycemic control in patients with T2DM who switched from premixed insulin to insulin glargine $100 \mathrm{U} / \mathrm{mL}$ (Gla-100).

A multicentre, prospective, observational study (i-Talent) conducted between 2012 and 2014. Data were collected at three routine visits at Months 0,3 and 6 from thirty public and private hospital centres involved in the management of T2DM from the United Arab Emirates, Kuwait and Qatar participated in this study. At baseline, patients were switched to Gla-100 at the dose chosen by the physician. Oral antidiabetic drugs could also be prescribed.

Overall, 440 people were enrolled and 357 were analysed $(68.2 \%$ men; mean age: $50.5 \pm 10.0$ years). The primary outcome was the change in $\mathrm{HbA1c}$ from baseline to 6 months. Secondary endpoints included the proportion of patients reaching HbAlc target $(<7 \%)$, insulin dose, weight change and hypoglycaemic events. We found that mean HbA1c levels decreased significantly from $9.3 \% \pm 1.5 \%$ to $7.5 \% \pm 0.8 \%$ at 6 months $(p<0.001) .22 .1 \%$ of patients achieved HbA1c target $<7.0 \%$. Mean daily Gla-100 dose at 6 months was $32.4 \pm 10.7$ U/day. A mean body weight reduction of $0.75 \pm 3.7 \mathrm{~kg}$ was observed. Overall, $3.4 \%$ of participants (15/380) reported 33 hypoglycemic events. In conclusion, T2DM patients from the Gulf region, inadequately controlled on a premixed insulin regimen may benefit from a switch to a basal insulin strategy with insulin glargine. While improving clinical outcomes in everyday clinical practice, insulin glargine treatment was well tolerated with a low incidence of hypoglycemia and no gain in body weight. 


\section{Introduction:-}

Type 2 diabetes mellitus (T2DM) is a metabolic disorder characterised by hyperglycemia in the context of insulin resistance and relative insulin deficiency (Inzucchi et al., 2012). Worldwide, the estimated prevalence of T2DM in adults (20-79 years) has risen from $2.8 \%$ in 2000, to $6.4 \%$ in 2010 and to $8.3 \%$ in 201 (Inzucchi et al., 2012, Wild et al., 2004, Shaw et al., 2010). Accordingly, the total number of people with diabetes is projected to rise from 171 million in 2000 to 382 million in 2013 up to 439 million in 2030. The North American and Caribbean region has the highest prevalence $(11 \%)$, with 37 million people affected, followed by the Middle East and North Africa with a prevalence of 9.2\% and 35 million affected people (Inzucchi et al., 2012). In 2013, the ten countries with the highest prevalence of T2DM in the world included Saudi Arabia (23.9\%), Kuwait (23.1\%) and Qatar (22.9\%) (Inzucchi et al., 2012).

Treatment of diabetes involves achieving and maintaining adequate blood glucose control and prevention and management of complications. Lifestyle intervention is an important component of the management of patients with T2DM, who should be strongly encouraged to diet and exercise. However, pharmacological management is required when lifestyle interventions are insufficient to achieve adequate glycaemic control and the vast majority of patients with T2DM will need to take antidiabetic medication at some stage.

Over the last fifteen years, standards of care have evolved with respect both to treatment goals and to available treatments. Following the demonstration that tight control of glycaemia can reduce the risk of complications (Wild et al., 2004), current treatment guidelines recommend regular monitoring of HbA1c during treatment and increasing the therapeutic pressure if target HbA1c levels are not met by using increasingly intensive therapeutic regimens (Shaw et al., 2010). Insulin therapy is recommended for patients who fail to achieve or maintain HbA1c targets with OAD therapy. This strategy has led to more patients with T2DM being treated with insulin, and these patients starting inuslin earlier in the disease course than was previously the case. This evolution has been accompanied by the development of new insulin administration devices, which increase patient confort and adherence, and particularly by the the development of recombinant insulin analogs with modified duration of action. In this context, long-acting basal insulins, which provide more stable insulin levels over the day than standard NPH insulin (International Diabetes Federation, 2013), thus providing improved glycemic control with a lower risk of hypoglycemia have now become the mainstay of insulin therapy in T2DM.

Premixed insulins combine long- and short-acting insulins in a single preparation injected once or twice daily. They do not mimic physiologic insulin profiles although more recent analog mixtures may offer a closer equivalent (Gary et al., 2017). The relative benefits of treatment with premix insulin compared to treatment with a basal insulin have been explored in a number of studies. A randomised clinical trial performed in Germany showed that the proportion of patients achieving $\mathrm{HbAlc} \leq 7 \%$ without confirmed nocturnal hypoglycemia was higher with insulin glargine plus OAD than with premixed insulin in combination with OAD therapy (Peterson, 2006). In addition, several observational studies, conducted principally in Europe, have reported that switching patients sub-optimally controlled with premixed insulin to insulin glargine improved glycemic control (Roach et al., 1999, Janka, 2005, Hammer, 2007, and Schiel et al., 2008). It is important to extend these observations to other populations in which dietary habits, notably the distribution of carbohydrate intake over the day, and the distribution of other risk factors for poor glycemic control may be different from European populations. The Middle East is of interest in this respect due to the high prevalence of diabetes and the widespread consumption of a sugar-rich diet.

The objective of the i-TALENT study was to investigate the effects of a basal insulin treatment with insulin glargine $100 \mathrm{U} / \mathrm{mL}$ on glycemic control and safety aspects in people with T2DM from the Gulf region (United Arab Emirates, Kuwait and Qatar), who were switched from a premixed insulin regimen in everyday clinical practice

\section{Methods:-}

\section{Study design:-}

The i-Talent study was a multicentre, prospective, observational study conducted in 30 centres involved in the management of diabetes mellitus in the United Arab Emirates (UAE), Kuwait, and Qatar. The study was conducted over a period of six months between October 2012 and March 2014.

\section{Study population:-}

Participating centres represented general practitioners, internists, endocrinologists and diabetologists, who were selected randomly from national lists. 
Adult patients with a diagnosis of T2DM and treated with a premixed insulin bid for $\geq 3$ months but $\leq 2$ years prior to screening, who failed to achieve adequate glycemic control (defined by HbA1c $>7 \%$ ), and for whom the physician had made the independent decision to switch therapy from a premixed insulin to insulin glargine $100 \mathrm{U} / \mathrm{mL}$ were eligible for the study.

Patients with type 1 diabetes mellitus, pregnant or breastfeeding women or those of childbearing potential who were not taking adequate contraceptive protection were excluded. Patients with contra-indications to insulin glargine, with a body mass index (BMI) $<25 \mathrm{~kg} / \mathrm{m}^{2}$ or $>35 \mathrm{~kg} / \mathrm{m}^{2}$, with severe renal or hepatic failure, treated with systemic corticosteroids, unlikely to comply with the study protocol and those who participating in another study were also excluded.

\section{Study procedures and data collection:-}

Each participating physician was expected to include at least 15 patients recruited consecutively during routine visits. The decision to prescribe insulin glargine as a part of the new treatment plan was at the physician's discretion and in accordance with ADA/EASD 2012 guidelines $^{3}$ and the condition of the patient. The dose regimen of insulin glargine was decided by the investigator on the basis of the prescribing information. The physician could also prescribe an oral antidiabetic drug (OAD) in addition to insulin glargine if this was considered beneficial for the patient.

Data were collected at three routine visits at baseline (Visit 1), three months later (Visit 2) and six months later (Visit 3). At Visit 1, the physician verified the inclusion criteria and obtained signed consent from participating patients. Data on sociodemographics and medical history was obtained. In addition, investigators documented diabetes-related variables (history of antidiabetic treatment, premixed insulin regimen previously prescribed, insulin glargine regimen prescribed at this visit, levels of $\mathrm{HbAlc}$ within the two last months, and fasting plasma glucose (FPG) levels. At Visits 2 and 3, the investigator re-evaluated the use of insulin glargine and decided whether to continue treatment. During this visit, the investigator also documented the latest levels of HbA1c and FPG as well as the type of oral antidiabetic treatment, any occurrence of hypoglycemic episodes (asymptomatic, defined as a measured blood glucose level $<70 \mathrm{mg} / \mathrm{dl}$ not associated with clinical symptoms; symptomatic, defined as an event with clinical symptoms that are considered to result from hypoglycemia (biologically confirmed or not); nocturnal hypoglycemia occuring while the patient is asleep; severe symptomatic hypoglycemia, defined as an event with clinical symptoms that are considered to result from hypoglycemia in which the patient required the assistance of another person) and other adverse events (AEs) following the use of insulin glargine. All AEs regardless of seriousness or relationship to treatment were recorded.

Data were validated for quality by checking for completeness, discrepancies, and inconsistencies for the first five patients enrolled in at least ten percent of active sites (those enrolling at least one patient) chosen at random.

\section{Study endpoints:-}

The primary endpoint was the change in HbA1c between Visit 1 (initiation of insulin glargine) and Visit 3 (six months later). Secondary endpoints were change in HbA1c between Visit 1 and Visit 2 (three months later), the proportion of patients reaching the target level of $\mathrm{HbA} 1 \mathrm{c}<7 \%$ at Vists 2 and 3, changes in FPG between Visit 1 and Visits 2 and 3, and occurrence of adverse events.

\section{Statistical analysis:-}

The target number of patients to be included was determined by a priori power calculations. According to Sharplin et al ${ }^{10}, 33 \%$ of patients with T2DM $(n=345)$ achieved a reduction in HbAlc of $\geq 1 \%$ in the twelve months following switch from premixed insulin to insulin glargine. In our study, we anticipated that at least $38 \%$ of patients included in our study would achieve a reduction in HbA1c of $\geq 1 \%$ after six months. In order to detect this proportion of patients with an alpha risk of 0.05 , we estimated that a sample size of 377 would be required. Considering a potential drop-out rate of $20 \%$, then 452 patients would be required. It was thus planned to recruit a total of 480 patients, with a minimum of 15 patients by centre with a distribution by country as follows: UAE 255 patients, Kuwait 150 patients and Qatar 75 patients.

All enrolled patients were included in the final analysis, which was performed on data pooled from all three participating countries. Demographic and clinical variables were described as mean \pm standard deviation (SD) and median (range) values for quantitative variables, and as numbers and frequencies (\%) for categorical variables. The 
statistical significance of between-group differences was estimated using the $\chi^{2}$ test, Student's $t$-test, analysis of variance or non-parametric tests as appropriate. All statistical tests were two-tailed tests with a 5\% threshold of significance. Statistical analysis was performed using SPSS software, version 17 (SPSS Inc., Chicago, USA).

\section{Ethics:-}

The study was performed in accordance with the Guidelines of Good Epidemiology Practice and corresponding local regulations, including data protection regulations. A written informed consent was obtained from all eligible patients. No patient was offered any financial incentive to participate in the study (Davies et al., 2008).

\section{Results:-}

The analysis was performed on data pooled from all three participating countries. Thirty centres participated in the study, including 18 in UAE, 9 in Kuwait and 3 in Qatar.

\section{Study population:-}

The flow of patients through the study is illustrated in Figure 1. A total of 440 patients were enrolled in the study, including 243 patients $(55.2 \%)$ in UAE, 157 patients (35.7\%) in Kuwait and 40 patients $(9.1 \%)$ in Qatar. Sixty of these patients infringed the study's eligibility criteria, leaving a study population of 380 eligible patients (86.4\%). A further 23 patients could not be analysed for the primary endpoint as they failed to complete six months of treatment.

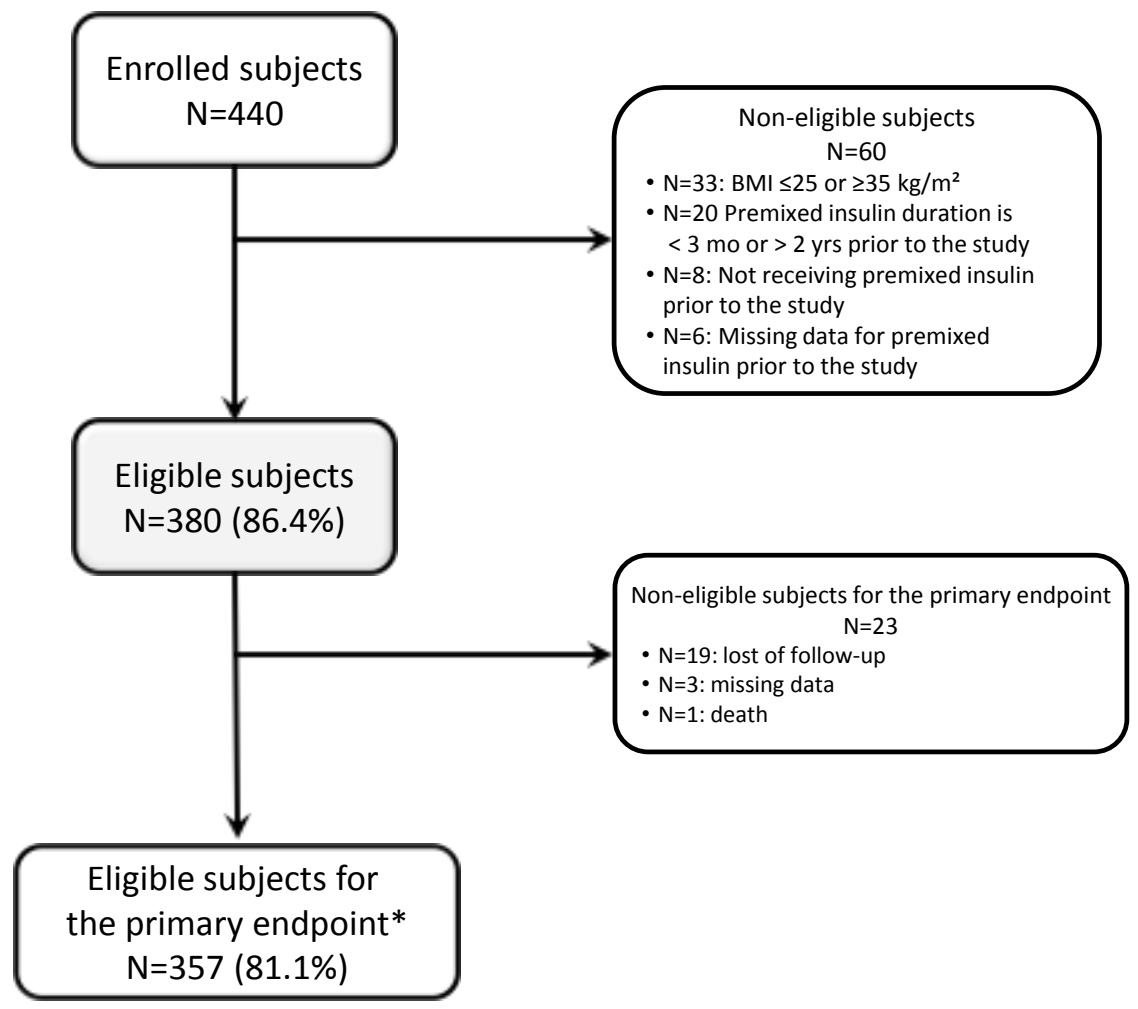

Figure 1:- Disposition of the study population. *Subjects with documented HbA1c values during the study period (Visits 1 \& 3).

The characteristics of the study population at baseline are presented in Table 1. Overall, the majority of patients were men with a mean age of $>50$ years. The mean values for HbA1c and FPG at inclusion were $9.3 \pm 1.5 \%$ and $185 \pm 48 \mathrm{mg} / \mathrm{dl}$ respectively. The mean duration of T2DM was $6.6 \pm 4.8$ years and 312 patients $(82.1 \%)$ had a family history of diabetes. 
Table 1:- Baseline characteristics of patients switching from premixed to insulin glargine.

\begin{tabular}{|c|c|}
\hline & $\begin{array}{c}\text { Total } \\
(\mathbf{N}=\mathbf{3 8 0})\end{array}$ \\
\hline Gender (men) & $259(68.2 \%)$ \\
\hline Age (years) & $50.5 \pm 10.0$ \\
\hline BMI $\left(\mathrm{Kg} / \mathrm{m}^{2}\right)$ & $29.2 \pm 2.9$ \\
\hline \multicolumn{2}{|l|}{ Diabetes mellitus } \\
\hline Family history & $312(82.1 \%)$ \\
\hline Late complications of diabetes & $149(39.0 \%)$ \\
\hline Diabetic neuropathy & $97(25.5 \%)$ \\
\hline Diabetic retinopathy & $56(14.7 \%)$ \\
\hline Diabetic nephropathy & $50(13.2 \%)$ \\
\hline Coronary artery disorders & $24(6.3 \%)$ \\
\hline Myocardial infarction & $16(4.2 \%)$ \\
\hline Cerebrovascular accident & $6(1.6 \%)$ \\
\hline Hypertension & $116(30.5 \%)$ \\
\hline Dyslipidemia & $76(20.0 \%)$ \\
\hline \multicolumn{2}{|l|}{ History of anti-diabetic treatment } \\
\hline Biguanides & $341(89.7 \%)$ \\
\hline Sulfonylureas & $220(57.9 \%)$ \\
\hline DPP-IV inhibitors & $133(35.0 \%)$ \\
\hline Short-acting insulin & $57(15.0 \%)$ \\
\hline Concomitant medications & $276(72.63 \%)$ \\
\hline Antihypertensives & $207(54.5 \%)$ \\
\hline Lipid lowring agents & $192(50.5 \%)$ \\
\hline Anti-platelet agents & $122(32.1 \%)$ \\
\hline
\end{tabular}

\section{Treatment:-}

Analysis of premixed insulin regimens at baseline before switching to insulin glargine revealed that premixed human insulin was used by 191 patients (50.3\%) and premixed insulin analogs by 189 patients $(49.7 \%)$.

The mean dose of insulin glargine prescribed for all eligible patients $(\mathrm{N}=380)$ at baseline was $26.7 \pm 11.5 \mathrm{U} / \mathrm{day}$ $(0.3 \pm 0.1 \mathrm{U} / \mathrm{kg})$. In the population who completeted the study at 6 months $(\mathrm{N}=357)$, the mean insulin glargine dose at baseline was $26.6 \pm 11.3 \mathrm{U} /$ day $(0.32 \pm 0.13 \mathrm{U} / \mathrm{kg})$. Titration of insulin glargine occurred only slightly over the course of the study to $28.3 \pm 10.6 \mathrm{U} /$ day at 3 months to $32.4 \pm 10.7 \mathrm{U} /$ day $(0.40 \pm 0.14 \mathrm{U} / \mathrm{kg})$ at $6 \mathrm{months}$. At initiation of insulin glargine, oral antidiabetic treatment was continued in all patients. The mean number of OADs was $1.9 \pm 0.8$ OAD per patient. These consisted principally of biguanides, prescribed in $90 \%, 91.3 \%$ and $91.0 \%$ of patients respectively at baseline, 3 months, and 6 months.

\section{Change in HbA1c levels:-}

HbA1c values at baseline (initiation of insulin glargine) and after 6 months were available for 357 patients. Mean HbA1c significantly decreased from $9.3 \% \pm 1.5 \%$ to $8.1 \pm 1.0 \%$ at 3 months and to $7.5 \% \pm 0.8 \%$ at 6 months $(p<$ 0.001 ; Wilcoxon signed-rank test). The mean HbA1c reduction at 6 month was $1.8 \% \pm 1.9$.

Table 2:- Change of HbA1c levels and fasting blood glucose during the observational study period.

\begin{tabular}{|c|c|c|c|}
\hline HbA1c (\%) & $\begin{array}{c}\text { Baseline (Visit 1) } \\
\text { N=357) }\end{array}$ & $\begin{array}{c}3 \text { months (Visit 2) } \\
(\mathrm{N}=354)\end{array}$ & $\begin{array}{c}6 \text { months (Visit 3) } \\
(\mathrm{N}=357)\end{array}$ \\
\hline Mean \pm SD & $9.3 \pm 1.5$ & $8.1 \pm 1.0$ & $7.5 \pm 0.8$ \\
\hline Median & 8.9 & 7.9 & 7.3 \\
\hline [Min-Max] & {$[7.2-16.0]$} & {$[6.1-14.0]$} & {$[5.8-12.3]$} \\
\hline Mean reduction & - & $1.1 \pm 1.1$ & $1.8 \pm 1.9$ \\
\hline Lower $95 \%$ CI & - & 0.99 & 1.6 \\
\hline Upper 95\% CI & - & 1.2 & 1.9 \\
\hline FPG (mg/dl) & $\begin{array}{c}\text { Baseline (Visit 1) } \\
\mathrm{N}=\mathbf{3 5 6})\end{array}$ & $\begin{array}{c}3 \text { months (Visit } 2) \\
(N=355)\end{array}$ & $\begin{array}{c}6 \text { months (Visit 3) } \\
(\mathrm{N}=354)\end{array}$ \\
\hline
\end{tabular}




\begin{tabular}{|l|c|c|c|}
\hline Mean \pm SD & $185 \pm 47.5$ & $148.4 \pm 29.9$ & $129.6 \pm 23.0$ \\
\hline Median & 173 & 142 & 126 \\
\hline$[$ Min-Max] & {$[105-374]$} & {$[84-311]$} & {$[73-235]$} \\
\hline Mean reduction & - & $36.9 \pm 37.5$ & $55.4 \pm 43.2$ \\
\hline Lower 95\% CI & - & 33 & 50.9 \\
\hline Upper 95\% CI & - & 40.7 & 59.8 \\
\hline
\end{tabular}

Overall, 16 (4.5\%) and 79 patients (22.1\%) achieved an HbA1c level of <7\% at 3 and 6 months, respectively. A reduction in $\mathrm{HbAlc}$ of $\geq 1 \%$ after 6 months of Gla-100 treatment was achieved in 258 patients $(72.3 \%)$.

\section{FPG levels:-}

Mean FPG was significantly reduced from $185 \pm 47.5 \mathrm{mg} / \mathrm{dL}$ at baseline to $129.6 \pm 23.0$ at 6 months $(p<0.001$; Wilcoxon signed-rank test) (Table 2). The mean reduction of FPG was $55.4 \pm 48.2 \mathrm{mg} / \mathrm{dL}$.

\section{Body weight:-}

Baseline mean body weight of $82.2 \pm 11.4 \mathrm{~kg}$ decreased significantly at 3 and 6 months $(81.7 \pm 11.4 \mathrm{~kg}$ and $81.4 \pm$ $11.4 \mathrm{~kg} ; \mathrm{p}<0.001)$. The mean reduction in weight was $0.75 \pm 3.7 \mathrm{~kg}$ at 6 months.

\section{Adverse events including hypoglycemia:-}

The analysis of potential adverse events was performed in the enrolled population $(\mathrm{N}=440)$. During the six months of follow-up, a total of seventeen patients (3.9\%) experienced 35 adverse events (AEs) during the study period. The majority of these AEs corresponded to episodes of hypoglycemia, experienced by $3.4 \%$ patients (15/440), who reported a total of 33 events including 25 symptomatic events and 8 asymptomatic events. The corresponding incidence rate of hypoglycemia was 15 events/100 patient.years (Table 3). Four hundred and twenty five (96.6\% of safety population) patients have not experienced any hypoglycemic event during the study duration, six patients experienced one episode, two patients two episodes, five patients three episodes and two patients four episodes. None of these episodes of hypoglycemia were considered to be serious and none required the assistance of a third party.

Table 3:- Incidence of hypoglycemia during the study period.

\begin{tabular}{|l|c|c|}
\hline \multicolumn{1}{|c|}{ Type of hypoglycemia } & $\begin{array}{c}\text { Incidence } \\
\mathbf{N = 3 3}\end{array}$ & number of events/100 patients/6 months \\
\hline Symptomatic & $25(75.8 \%)$ & 5.7 \\
\hline Asymptomatic & $8(24.2 \%)$ & 1.8 \\
\hline Nocturnal & $3(9.1 \%)$ & 0.7 \\
\hline Severe (Assistance required) & $0(0.0 \%)$ & - \\
\hline Countermeasures & & 2.3 \\
Oral carbohydrate & $10(30.3 \%)$ & 0.0 \\
Glucagon & $0(0.0 \%)$ & 0.0 \\
IV glucose & $0(0.0 \%)$ & - \\
\hline Serious hypoglycaemia & $0(0.0 \%)$ & \\
\hline
\end{tabular}

With respect to adverse events other than hypoglycemia, two events were reported in two $(0.45 \%)$ patients. One of these events was mild non-serious headache and the other was a severe serious sepsis on top of a diabetic foot, which resulted in death. Neither of these two events was considered by the physician to be related to insulin glargine.

\section{Discussion:-}

The i-Talent observational study performed in UAE, Kuwait and Qatar showed that in patients with type 2 diabetes mellitus sub-optimally controlled with premixed insulin, a switch to insulin glargine replacing premixed insulin and added to previous oral antihyperglycemic drugs was associated with a significant reduction in HbA1c, FPG, and body weight and with a low risk of hypoglycemia.

Despite the fact that the study population received a previous premixed insulin treatment and presented a relatively short duration of diabetes ( $6.6 \pm 4.8$ years), the study population already had a poorly controlled glycemic condition 
at initiation of switch (mean HbA1c was $9.3 \pm 1.5 \%$ ) with almost half of the population experiencing diabetic complications.

The efficacy of the insulin glargine regimen was demonstrated by a statistically significant $(p<0.001)$ reduction of HbA1cat 6 months with a mean reduction of $1.8 \%$. These findings can be compared to those reported by other observational studies in patients switching from premixed- to glargine-based regimen. For example, a sub-group analysis of the AT.LANTUS Study including 686 patients showed that mean HbA1c levels decreased by $1.0 \%$ six months after the switch. Another study performed in 345 patients in the UK (Hammer, 2007, and Schiel et al., 2008), showed that mean HbA1c decreased by $0.75 \%$ six months after the switch, which is approximately half the decrease observed in our study. Interestingly, $22.1 \%$ of patients reached an HbA1c level of $<7 \%$ which is slightly lower than that of the UK study (35\%) (Schiel et al., 2008). These different responder rates may be explained by differences in follow-up duration, baseline HbA1c levels or risk factors for treatment response, such as obesity (Sharplin et al., 2009), between the studies. In our study, the duration of follow-up was relatively short (six months), and responder rates may have continued to rise over time. Nonetheless, all studies have shown that glycemic control remains suboptimal in many patients switched from a premixed insulin to a basal insulin, and such patients may benefit from addition of a fast-acting prandial insulin (International Epidemiologiocal Association, 2007).

In parallel to the HbA1c reduction, a significant FPG reduction was observed after three $(-37 \mathrm{mg} / \mathrm{dl})$ and six months $(-55 \mathrm{mg} / \mathrm{dl})$ after the switch. These findings are supported by data from the literature. For example, the AT.LANTUS study reported a mean FPG decrease of $60 \mathrm{mg} / \mathrm{dl}$ six months after the switch to glargine. Overall, the reductions of HbA1c and FPG levels, found in our study following the switch from premixed to glargine insulin, are thus comparable to the findings of other studies (Hammer, 2007, and Schiel et al., 2008, Yki-Jarvinen et al., 2001).

The safety profile of insulin glargine was assessed by documenting the occurrence of hypoglycemic events, of other adverse events and of body weight changes for the enrolled subjects over the six months study duration. Only a small number (3.9\%) of patients reported any adverse event, of which hypoglycemia was the most frequently reported (33 out of 35 events), demonstrating a good tolerability profile of insulin glargine in everyday clinical practice. A study from Germany perfomed in 5045 patients using a comparable methodology to that of our study showed that hypoglycemia was the most commonly reported adverse event and represented half of all events (Roach, 1999). Furthermore, our study showed that none of the reported episodes were serious or severe. The results presented here show that switching patients with type 2 diabetes not optimally controlled on premixed insulin to an insulin glargine-based regimen is well tolerated and that the risk of hypoglycemia is low.

By nature of the design, the study has several limitations. The lack of a comparator makes it difficult to assess the specific effect of insulin glargine. However, the improvements in glycemic control over the study period are consistent with previous randomised controlled trials performed in patients not optimally controlled with premixed insulin and who switched to insulin glargine (Inzucchi, 2015, Aschner et al., 2015). Secondly, the decision to initiate insulin glargine was not based on a planned treatment algorithm but was made at the discretion of the physician at the consultation visit. This may have introduced an inclusion bias if the decision to switch was a consequence of the phyicisan's participation in the study and not made independently. Furthermore, we acknowledge that no attempt was made to adjust data on $\mathrm{HbAlc}$ for potential confounding factors such as demographics, ethnicity, weight, hypoglycemia, other laboratory tests, concomitant use of OADs and presence of comorbidities. The incidence of hypoglycemia may also reflect the self-reporting methods used, as patients and physicians did not document details of each episode systematically. Consequently, the occurrence of hypoglycemia may have been under-reported.

\section{Conclusion:-}

This prospective study conducted in UAE, Kuwait and Qatar showed that in everyday clinical practice switching to insulin glargine may be a useful strategy for improving glycemic control in T2DM patients who do not respond adequately to premixed insulin. Switching to glargine significantly improved glycemic control, with no gain in body weight and a low incidence of hypoglycemia.

\section{Acknowledgements:-}

The i-TALENT study was supported by Sanofi. The authors thank all i-TALENT study investigators for their contribution. The authors also acknowledge writing and editing assistance in developing this manuscript by FOXYMED, funded by Sanofi. 


\section{Conflict of Interest Statement:-}

H. Penninckx has a scientific collaboration with Sanofi, he however has no conflict of interest with the writing of this paper. Mohammed Ismail is employed by Sanofi.

\section{Funding:-}

This study was funded by Sanofi Gulf Countries

\section{References:-}

1. Aschner P, Sethi B, Gomez-Peralta F, et al. Insulin glargine compared with premixed insulin for management of insulin-naive type 2 diabetes patients uncontrolled on oral antidiabetic drugs: the open-label, randomized GALAPAGOS study. Journal of diabetes and its complications. 2015.

2. Davies M, Sinnassamy P, Storms F, Gomis R, Group ALS. Insulin glargine-based therapy improves glycemic control in patients with type 2 diabetes sub-optimally controlled on premixed insulin therapies. Diabetes Res Clin Pract. 2008;79(2):368-375.

3. Gary Deed et al., Use of 50/50 Premixed Insulin Analogs in Type 2 Diabetes: Systematic Review and Clinical Recommendations. Diabetes Therapy. 2017 Dec; 8(6): 1265-1296.

4. Hammer H, Klinge A. Patients with type 2 diabetes inadequately controlled on premixed insulin: effect of initiating insulin glargine plus oral antidiabetic agents on glycaemic control in daily practice. International journal of clinical practice. 2007;61(12):2009-2018.

5. International Epidemiologiocal Association - European Federation. Good Epidemiological Practice (GEP): proper conduct in epidemiology research. 2007.

6. International Diabetes Federation. IDF Diabetes Atlas, sixth edition. 2013.

7. Inzucchi SE, Bergenstal RM, Buse JB, et al. Management of hyperglycemia in type 2 diabetes: a patientcentered approach: position statement of the American Diabetes Association (ADA) and the European Association for the Study of Diabetes (EASD). Diabetes care. 2012;35(6):1364-1379.

8. Inzucchi SE, Bergenstal RM, Buse JB, et al. Management of hyperglycemia in type 2 diabetes, 2015: a patient-centered approach: update to a position statement of the American Diabetes Association and the European Association for the Study of Diabetes. Diabetes care. 2015;38(1):140-149.

9. Janka HU, Plewe G, Riddle MC, Kliebe-Frisch C, Schweitzer MA, Yki-Jarvinen H. Comparison of basal insulin added to oral agents versus twice-daily premixed insulin as initial insulin therapy for type 2 diabetes. Diabetes care. 2005;28(2):254-259.

10. Peterson GE. Intermediate and long-acting insulins: a review of NPH insulin, insulin glargine and insulin detemir. Current medical research and opinion. 2006;22(12):2613-2619.

11. Roach P, Trautmann M, Arora V, Sun B, Anderson JH, Jr. Improved postprandial blood glucose control and reduced nocturnal hypoglycemia during treatment with two novel insulin lispro-protamine formulations, insulin lispro mix25 and insulin lispro mix50. Mix50 Study Group. Clinical therapeutics. 1999;21(3):523-534.

12. Shaw JE, Sicree RA, Zimmet PZ. Global estimates of the prevalence of diabetes for 2010 and 2030. Diabetes Res Clin Pract. 2010;87(1):4-14.

13. Schiel R, Muller UA. Efficacy and treatment satisfaction of once-daily insulin glargine plus one or two oral antidiabetic agents versus continuing premixed human insulin in patients with Type 2 diabetes previously on long-term conventional insulin therapy: the SWITCH Pilot Study. Exp Clin Endocrinol Diabetes. 2008;116(1):58-64.

14. Sharplin P, Gordon J, Peters JR, Tetlow AP, Longman AJ, McEwan P. Switching from premixed insulin to glargine-based insulin regimen improves glycaemic control in patients with type 1 or type 2 diabetes: a retrospective primary-care-based analysis. Cardiovasc Diabetol. 2009;8:9.

15. Wild S, Roglic G, Green A, Sicree R, King H. Global prevalence of diabetes: estimates for the year 2000 and projections for 2030. Diabetes care. 2004;27(5):1047-1053.

16. Yki-Jarvinen H. Combination therapies with insulin in type 2 diabetes. Diabetes care. 2001;24(4):758-767. 